\section{Comparing Lymphocyte Radiosensitivity of Prostate Cancer Patients with Healthy Donors Using Micronuclei and Chemical Premature Chromosome Condensation Tests}

\author{
Golfam F. ${ }^{1 \oplus}$, Hashemi B. ${ }^{2 * \odot}{ }^{\circ}$, Haeri A. ${ }^{3}$, Nikoofar A. ${ }^{4}$
}

\begin{abstract}
Background: Cytogenetic tests are usually used for diagnosing predisposed individuals to cancer by determining their lymphocyte radiosensitivity.

Objective: To determine the potential role of radiosensitivity in predisposition of prostate cancer by comparing lymphocyte radiosensitivity of prostate cancer patients with healthy donors.

Materials and Methods: In this experimental study, the blood samples of 10 prostate cancer patients and 10 healthy donors were irradiated to $0.25,0.5,1,2,4$ and 6 Gy ionizing radiation produced by a $6 \mathrm{MV}$ Linac. One sample of each group receiving no radiation was regarded as the background. The micronuclei (MN) and chemical premature chromosome condensation (PCC) cytogenetic tests were performed on all samples and the numbers of $\mathrm{MN}$ and PCC rings were scored. Dose-response curves were plotted for both healthy and cancerous groups with two tests.
\end{abstract}

Results: There was a significant difference between the numbers of MN within each group due to different levels of radiation doses. There was also a significant difference between the two groups in all identical doses, with the exception of $6 \mathrm{~Gy}$. The chemical PCC test indicated a significant difference between the scored PCC rings in each group at doses higher than $0.25 \mathrm{~Gy}$. However, no differences were noted between the healthy donors and prostate cancer patients receiving the same level of doses.

Conclusion: MN test can be considered as a reliable indicator of predisposition of prostate cancer. On the other hand, the chemical PCC test could not differentiate between healthy donors and prostate cancer patients at the dose range examined in this study.

Citation: Golfam F, Hashemi B, Haeri A, Nikoofar A. Comparing Lymphocyte Radiosensitivity of Prostate Cancer Patients with Healthy Donors Using Micronuclei and Chemical Premature Chromosome Condensation Tests. J Biomed Phys Eng. 2020;10(4):411-420. doi: 10.31661/JBPE.V0I0.657.

\section{Keywords}

Micronuclei Tests; Cytogenetic Analysis; Radiation Tolerance; Dose-Response Relationship; Prostatic Neoplasms

\section{Introduction}

hromosomes are permanently exposed to deleterious factors such as ionizing radiation, and are continuously injured. However, their recovery mechanisms repair such injuries and return them to their prime status. As people have different characteristics, their potentials of genomic repair are also different [1]; it means that for instance
${ }^{1} \mathrm{PhD}, \mathrm{MD}$, Department of Medical Physics, Faculty of Medical Sciences, Tarbiat Modares Univer-

sity, Tehran, Iran

${ }^{2} \mathrm{PhD}$, Associate Pro-

fessor, Department of

Medical Physics, Tarbiat

Modares University, Teh-

ran, Iran

${ }^{3} \mathrm{PhD}$, Assistant Profes-

sor, Nuclear Science and

Technology Research

Institute, Tehran, Iran

${ }^{4} \mathrm{MD}$, Associate Profes-

sor, Department of

Radiation Oncology,

Firouzgar Hospital, Iran

University of Medical Sci-

ences, Tehran, Iran

*Corresponding author:

B. Hashemi

Associate Professor,

Department of Medical

Physics, Faculty of Medi-

cal Sciences, Tarbiat

Modares University, Teh-

ran, Iran

E-mail: bhashemi@

modares.ac.ir

Received: 29 September 2016 Accepted: 24 October 2016 
the same chromosome aberration may occur in two cases, but their repair result may be different. For example, the repair process could be complete and authentic in one case, and wrong and imperfect in another case [2]. Since each change in genomic content might lead to a defect in cell normal activities and even resulting in cancer, it could be expected that the less capability of repairing chromosomes leads to a higher risk for the induction of cancer [3]. Impossibility of proper repairing of chromosomes could be detected by increased radiosensitivity. For instance, patients with specific syndromes such as Ataxia-Telangectasia who have problem repairing chromosomes, have an increased radiosensitivity and are predisposed to cancers $[4,5]$.

Different factors affect cancer risk; the most important of such factors are genetic and external factors. As a matter of fact, external factors which could lead to cancers, also act through genomic damages. Therefore, genetic investigation on individuals could reveal the effects of all risk factors. One way of genetic assessment in people is done by determining their chromosomes radiosensitivity through cytogenetic tests. In some cancers such as breast cancer, it can be shown that most patients have increased radiosensitivity compared to normal individuals [6].

In the early 1990s, some studies [7-11] have been conducted to investigate the possibility of cancer prediction in individuals based on the frequency of chromosomal aberrations in peripheral blood lymphocytes. In these studies, the chromosomal aberrations of normal individuals have been registered and followed for some years later and their results indicated a relation between the risk of cancer and chromosomal aberrations. Other studies were also performed in this field to compare healthy people with cancerous ones from radiosensitivity point of view using cytogenetic tests and determining whether these tests could be used as a predicting factor of cancers or not. Cytogenetic tests used in these studies include MN, dicentric, comet assay and FISH technique performed at $G_{0}$ or $G_{2}$ phases of cell cycle and on many kinds of cancers especially breast cancer [12-28].

In some studies, no differences have been reported in the background aberrations between healthy individuals and cancerous patients. However, significant differences have been recognized in the aberrations after irradiation [29]. Another remarkable point noted from some studies is that radiosensitive cancerous patients recognized by using various cytogenetic tests at different cell cycle phases are different from each other [29]. This means that detecting chromosomal aberrations by different tests and cell cycle phases have probably different mechanisms, and each test can show specific endpoints.

Borgmann et al., [13] used dicentric test for the comparison of healthy individuals and prostate cancer patients after irradiation of their lymphocytes in $\mathrm{G}_{0}$ and $\mathrm{G}_{2}$ phases. Their results showed that there was no significant difference between the two groups in $G_{0}$ unlike $G_{2}$ phase which demonstrated a significant difference.

Considering other researches registering differences between healthy individuals and cancerous patients using $\mathrm{MN}$ assay in $\mathrm{G}_{0}$ phase, Borgmann et al., declared that it was possible that the mechanism of identifying chromosomal aberrations was different in dicentric and $\mathrm{MN}$ assays or the radiosensitivity of lymphocytes in various cancers as being different [13].

Since prostate cancer is one of the most occurring cancers in men and regarding the importance of early diagnosis of this disease in its definite treatment, and based on Borgmann et al., results, in this study the MN assay was performed for comparing healthy individuals with prostate cancer patients. In addition, considering the chemical PCC test to show more aberration than dicentric test, the chemical PCC test was used simultaneously to investigate the possibility of using this test for 
Lymphocyte Radiosensitivity of Prostate Cancer

the comparison of radiosensitivity of the two groups.

\section{Material and Methods}

\section{Selection of patients and normal cases}

In this experimental study, ten new cases were selected from prostate cancer patients referred to a general hospital (Pars) in Tehran, Iran based on their prostate pathology result. The average age of the patients was 68 (5170) and all were in the stage 2 of prostate cancer. They had a Gleason score between 3 to 6 and PSA (Prostatic Specific Antigen) from 5.3 to 12 . Ten normal cases were selected with a mean age of 58 (57-70). None of the patients and normal cases had any background of other cancers, chemotherapy, radiotherapy, hormone therapy, occupational irradiation and smoking.

\section{Sample Preparation}

$7 \mathrm{ml}$ of blood was obtained by venipuncture using heparinized syringe from each person and divided into 14 microtubes. 6 pairs of the microtubes of each person were irradiated to $0.25,0.5,1,2,4$ and 6 Gy doses delivered by a 6 MV Siemens PRIMUS Linac. One pair of the samples of each person received no radiation for determining chromosomal aberrations background. The microtubes were transferred to a cytogenetic laboratory in a special impeding container during utmost 30 minutes. Then, each sample was added to $4.5 \mathrm{ml}$ RPMI-1640 supplemented with $1 \%$ penicillin-streptomycin plus $0.6 \mathrm{ml}$ of foetal calf serum (FCS), LGlutamine. Enough amount of PHA was added to each tube, to reach a final concentration of $20 \mu \mathrm{g} / \mathrm{mL}$. Finally, they were incubated at $37^{\circ} \mathrm{C}\left(5 \% \mathrm{CO}_{2}, 95 \%\right.$ humidity $)$.

\section{MN Assay}

24 hours after adding PHA, cytochalasin B was added to the samples chosen for the $\mathrm{MN}$ assay to have a final concentration of $6 \mu \mathrm{g} / \mathrm{mL}$ of it in each sample for preventing cytokine- sis. 72 hours after adding PHA, the cultured cells were centrifuged at $180 \mathrm{~g}$ for 7 minutes and their supernatant was removed and $7 \mathrm{ml}$ of $0.075 \mathrm{M} \mathrm{KCl}\left(4^{\circ} \mathrm{C}\right)$ was added to them (for the lysis of red blood cells). Afterwards, the cells were centrifuged and fixed in a mixture of methanol and acetic acid (6:1) after removing the supernatant. Then, the cells were centrifuged and washed with the fixative 3 times more. Finally, the fixed cells were dropped on precleaned slides and stained with 7\% Giemsa solution for 15 minutes. During the investigation of MN slides, the cells with 1, 2, 3, 4 or more nuclei were counted and labelled as M1, M2, M3, M4 and so on. Afterwards, the nuclear division index (NDI) was calculated from the following equation:

$$
\mathrm{NDI}=(\mathrm{M} 1+2 \mathrm{M} 2+3 \mathrm{M} 3+4 \mathrm{M} 4) / \mathrm{N}
$$

in which $\mathrm{N}$ is the total cells scored.

Micronuclei were counted in 1000 binucleated cells by using the criteria mentioned by Fenech et al, [30].

\section{Chemical PCC Test}

46 hours after adding PHA, colcemide was added to the cultures to have a concentration of $40 \mathrm{ng} / \mathrm{mL}$. One hour later, calyculin A was added to each culture to have a final concentration of $30 \mathrm{nM}$. One hour after adding calyculin $\mathrm{A}$, and centrifuging and removing supernatant, the cultured cells were treated with $0.075 \mathrm{M}$ $\mathrm{KCl}$ (reaching to a volume of $6 \mathrm{cc}$ ) and kept at $37^{\circ} \mathrm{C}$ for a period of 10 minutes. Then, they were fixed four times with a fixative (methanol: acetic acid 3:1) and centrifuged subsequently each time. At last, the fixed cells were dropped onto precleaned slides and stained with 7\% Giemsa solution for 15 minutes.

\section{Statistical Considerations}

Kruskal-Wallis non-parametric ANOVA and Mann-Whitney tests were used to analyze the relationship between the chromosomal aberrations and radiation doses in each group and also for the comparison of aberrations at identical doses between every two groups. 


\section{Results}

\section{MN Assay}

Results of MN tests for the two groups of healthy individuals and prostate cancer patients are summarized in Tables 1 and 2.

The linear-quadratic equations obtained for the healthy individuals and prostate cancer patients were $\mathrm{y}=0.0216 \mathrm{x}^{2}+0.0901 \mathrm{x}+0.033$ $\left(\mathrm{R}^{2}=0.9992\right)$ and $\mathrm{y}=0.0113 \mathrm{x}^{2}+0.1511 \mathrm{x}+$ $0.0452\left(\mathrm{R}^{2}=0.9967\right)$, respectively.

Even though the previous studies have indicated that the dose-response curves of micronuclei are linear-quadratic [31], the Chi-square test was also used to make sure of the good curve fitness. The $\chi^{2}$ and $p$ parameters for the healthy group were 3.446 and 0.632 and for the prostate cancer patients 3.369 and 0.643 , respectively showing that the linear-quadratic curve fitting is proper and also micronuclei distribution is in concordance with Poisson distribution. The $\sigma^{2} / \mu$ and $u$ parameters noted in Tables 1 and 2 were calculated for the comparison of the data distribution with Poisson distribution. The distribution of $\mathrm{MN}$ in binucleated cells (BC), with reference to the variance/mean per each radiation dose conforms to Poisson distribution. The mean amount of the $\mathrm{MN} / \mathrm{BC}$ increases when the doses rise from 0 to $6 \mathrm{~Gy}$. There are significant differences of the $\mathrm{MN} / \mathrm{BC}$ among all doses within each group $(\mathrm{P}<0.05)$. These significant differences were also proved with the LSD (least significant difference) test.

Comparing the identical radiation doses of the two groups indicated that at some level of doses the data were not independent ( $P$ value $=0.222$ ). Thus, for recognizing identical doses in the two groups having significant difference with each other, the $\mathrm{P}$ value was calculated for each level of doses separately. The calculated $\mathrm{P}$ for the doses of $0,0.25,0.5,1,2$, 4 and 6 Gy were $0.033,0.002,0.016,0.001$, $0.041,0.034,0.821$, respectively. This shows that except for the $6 \mathrm{~Gy}$, there is a significant difference between the yield of $\mathrm{MN}(\mathrm{MN} / \mathrm{BC})$ at identical radiation doses between the healthy individuals and prostate cancer patients.

The histogram chart of the micronuclei yields for the healthy individuals and prostate cancer patients has been illustrated in Figure 1 .

\section{Nuclear Division Index (NDI)}

The calculated values of NDI of the two groups are presented in Table 3.

Comparison of the NDI at identical doses showed a significant difference between the

Table 1: Analysis of the data related to the $\mathrm{MN}$ in prostate cancer patients

Cancer

\begin{tabular}{|c|c|c|c|c|c|c|c|c|c|c|c|c|c|}
\hline \multirow{2}{*}{$\begin{array}{l}\text { Dose } \\
\text { (Gy) }\end{array}$} & \multirow{2}{*}{$\begin{array}{l}\text { Total } \\
\text { MN }\end{array}$} & \multirow{2}{*}{ ield } & \multicolumn{7}{|c|}{ Micronuclei distribution } & & \multirow{2}{*}{$\sigma^{2} / \mu$} & \multirow{2}{*}{ SE } & \multirow{2}{*}{$\mathrm{Cl}(95 \%)$} \\
\hline & & & 0 & 1 & 2 & 3 & 4 & 5 & 6 & & & & \\
\hline 0 & & $0<03$ & 973 & 240 & 2 & 0 & 0 & 0 & 0 & 2.521 & 11 & .0027 & $0.0<2$ \\
\hline 0.25 & & 0712 & 9354 & 585 & 56 & 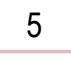 & 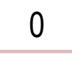 & 0 & 0 & 2.787 & 1.124 & 0.0058 & 0.058 \\
\hline 0.5 & 1528 & 0.1528 & 8861 & 854 & 194 & 78 & 13 & 0 & 0 & 9.522 & 1.425 & 0.0190 & 0.1959 \\
\hline 1 & 2394 & 0.2394 & 8240 & 1302 & 302 & 136 & 20 & 0 & 0 & 9.691 & 1.433 & 0.0154 & .2741 \\
\hline 2 & 3470 & 0.3470 & 7317 & 2134 & 384 & 132 & 43 & 0 & 0 & 5.904 & 1.264 & 0.0168 & $0.3090-0.3849$ \\
\hline 4 & & 0.8481 & 4633 & 3175 & 1549 & 409 & 210 & 27 & 1 & 3.709 & 1.166 & 0.0324 & $0.7748-0.9214$ \\
\hline 6 & 13543 & 1.3543 & 2176 & 3896 & 2684 & 833 & 299 & 88 & 24 & -3.154 & 0.859 & 0.0512 & $1.2384-1.4702$ \\
\hline
\end{tabular}

u: Normalized unit of dispersion index, $\sigma^{2} / \mu$ : Dispersion index, SE: Standard error, Cl: Confidence Interval 
Table 2: Analysis of the data related to the $\mathrm{MN}$ in the healthy individuals

Cancer

\begin{tabular}{|c|c|c|c|c|c|c|c|c|c|c|c|c|c|}
\hline \multirow{2}{*}{$\begin{array}{c}\text { Dose } \\
\text { (Gy) }\end{array}$} & \multirow{2}{*}{$\begin{array}{c}\text { Total } \\
\text { MN }\end{array}$} & \multirow{2}{*}{ Yield } & \multicolumn{7}{|c|}{ Micronuclei distribution } & & \multirow{2}{*}{$\sigma^{2} / \mu$} & \multirow{2}{*}{ SE } & \multirow{2}{*}{$\begin{array}{c}\mathrm{Cl} \\
(95 \%)\end{array}$} \\
\hline & & & 0 & 1 & 2 & 3 & 4 & 5 & 6 & & & & \\
\hline 0 & 2 & 204 & 9806 & 18 & 1 & 0 & 0 & 0 & & 1 & 75 & 0.0021 & 0.4 \\
\hline 0.25 & 441 & 0.0441 & 9624 & 308 & 65 & 0 & 0 & 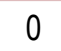 & & 5.955 & 1.264 & 0.0033 & 523 \\
\hline 0.5 & 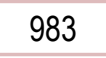 & 83 & 9252 & 546 & 169 & 3 & 0 & 0 & $\sigma$ & 4 & 11 & 0 & \\
\hline 1 & 1652 & 0.1652 & 8708 & 999 & 235 & 49 & 9 & 0 & 0 & 7.739 & 1.345 & 0.0061 & $0.1513-0.1791$ \\
\hline 2 & 2963 & 0.2963 & 7704 & 1792 & 362 & 121 & 21 & 0 & & 5.679 & 1.254 & 0.0185 & $0.2543-0.3383$ \\
\hline 4 & 7270 & 0.7270 & 4996 & 3214 & 1428 & 248 & 114 & 0 & 0 & 1.038 & 1.046 & 0.0459 & $0.6231-0.8309$ \\
\hline 6 & 13570 & 1.3570 & 1765 & 4098 & 3261 & 589 & 259 & 21 & 7 & -7.813 & 0.651 & 0.0520 & $1.2393-1.4747$ \\
\hline
\end{tabular}

u: Normalized unit of dispersion index, $\sigma^{2} / \mu$ : Dispersion index, SE: Standard error, Cl: Confidence Interval

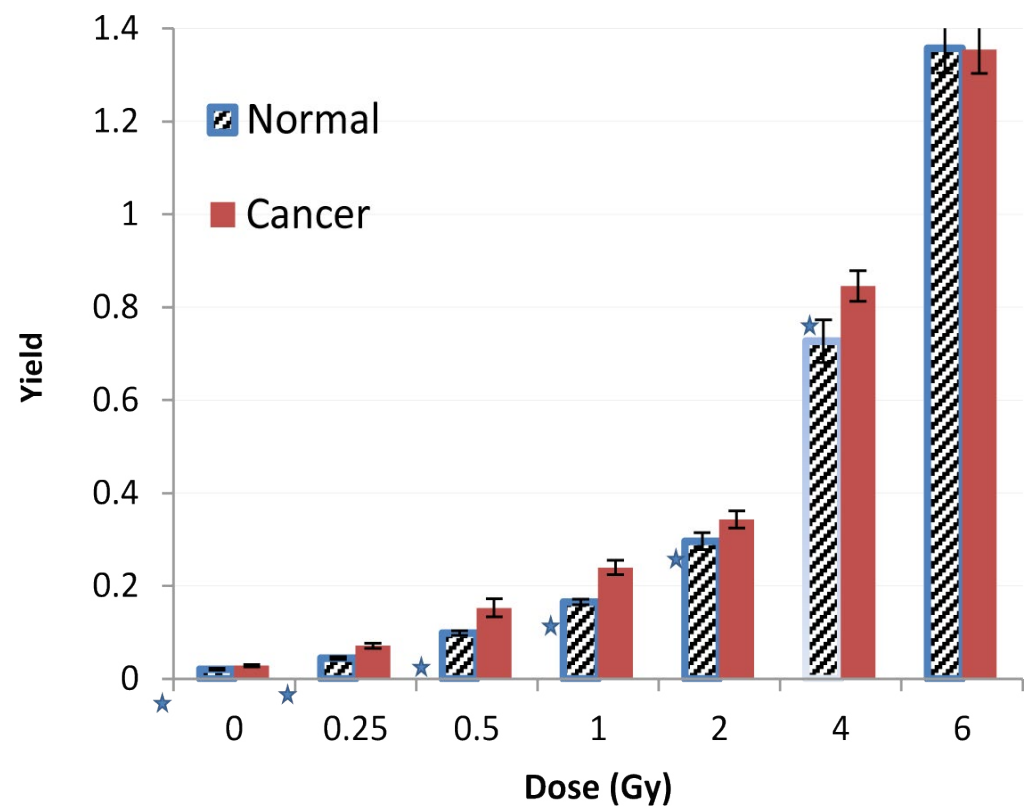

Figure 1: Comparison of the MN/BC for the healthy individuals (Normal) and prostate cancer patients (the stars indicate significant differences)

Table 3: The calculated NDI in the healthy (Normal) individuals and prostate cancer patients

\begin{tabular}{|c|c|c|c|c|c|c|c|}
\hline Cases & 0 & 0.25 & 0.5 & 1 & 2 & 4 & 6 \\
\hline Cancerous & 1.63 & 1.63 & 1.59 & 1.44 & 1.36 & 1.30 & 1.23 \\
\hline Normal & 1.62 & 1.62 & 1.64 & 1.46 & 1.40 & 1.32 & 1.26 \\
\hline
\end{tabular}


two groups $(\mathrm{P}<0.05)$ only at 0.5 and 6 Gy doses. Investigation of NDI within each group indicated significant differences for the doses from 0.5 to $6 \mathrm{~Gy}$ in healthy individuals and from 0.25 to $6 \mathrm{~Gy}$ in cancerous patients.

\section{Chemical PCC Test}

Frequency and distribution of PCC rings in irradiated lymphocytes at different radiation doses are presented in Tables 4 and 5 for the healthy and cancerous groups. The tables include the yields of aberrations (PCC rings/ cell), standard error and mean of the rings at

Table 4: Summary of the PCC rings data in the healthy individuals

\begin{tabular}{cccc}
$\begin{array}{c}\text { Dose } \\
\text { (Gy) }\end{array}$ & $\begin{array}{c}\text { Total } \\
\text { Ring }\end{array}$ & PCC Rings per Cell & SE \\
\hline 0 & 0 & 0 & 0 \\
\hline 0.25 & 0 & 0 & 0 \\
\hline 0.5 & 0 & 0 & 0 \\
\hline 1 & 15 & 0.0075 & 0.00011 \\
\hline 2 & 33 & 0.0165 & 0.00015 \\
\hline 4 & 139 & 0.0695 & 0.00027 \\
\hline 6 & 321 & 0.1605 & 0.00033 \\
\hline
\end{tabular}

SE: Standard Error

Table 5: Summary of the PCC rings data in the cancerous patients

\begin{tabular}{cccc}
$\begin{array}{c}\text { Dose } \\
\text { (Gy) }\end{array}$ & $\begin{array}{c}\text { Total } \\
\text { Ring }\end{array}$ & PCC Rings per Cell & SE \\
\hline 0 & 0 & 0 & 0 \\
\hline 0.25 & 0 & 0 & 0 \\
\hline 0.5 & 4 & 0.0020 & 0.00008 \\
\hline 1 & 15 & 0.0075 & 0.00008 \\
\hline 2 & 38 & 0.0190 & 0.00018 \\
\hline 4 & 135 & 0.0675 & 0.00023 \\
\hline 6 & 313 & 0.1565 & 0.00043 \\
\hline
\end{tabular}

SE: Standard Error each radiation dose level.

The PCC rings yields of the healthy individuals and prostate cancer patients at different doses are compared in Figure 2.

The linear-quadratic equation obtained by applying the regression method on the healthy individuals and cancerous patients were $\mathrm{Y}=0.0046 \mathrm{D}^{2}-0.008 \mathrm{D}+0.0004$ and $\mathrm{Y}=0.0043 \mathrm{D}^{2}+4 \mathrm{E}-05 \mathrm{D}+0.0008$, respectively $\left(\mathrm{R}^{2}=0.999\right)$.

Comparison of PCC rings at different radiation dose levels indicated a significant difference between the doses of $0.5,1,2,4$ and 6 Gy within each group. Meanwhile, comparison of the $\mathrm{PCC}$ rings at different identical radiation dose levels between the two groups showed no significant differences between the rings yields of the healthy individuals and prostate cancer patients at any doses. The $\mathrm{P}$ values for the doses investigated in this study (from 0 to 6 Gy) ranged from 0.14 to 1 .

\section{Discussion}

Cancer treatment imposes heavy costs on societies, and the incidence of cancers increases every year. Some cancers could be completely cured if diagnosed at primary steps and early stages. Therefore, early diagnosis of such malignancies could be life saving for many pa-

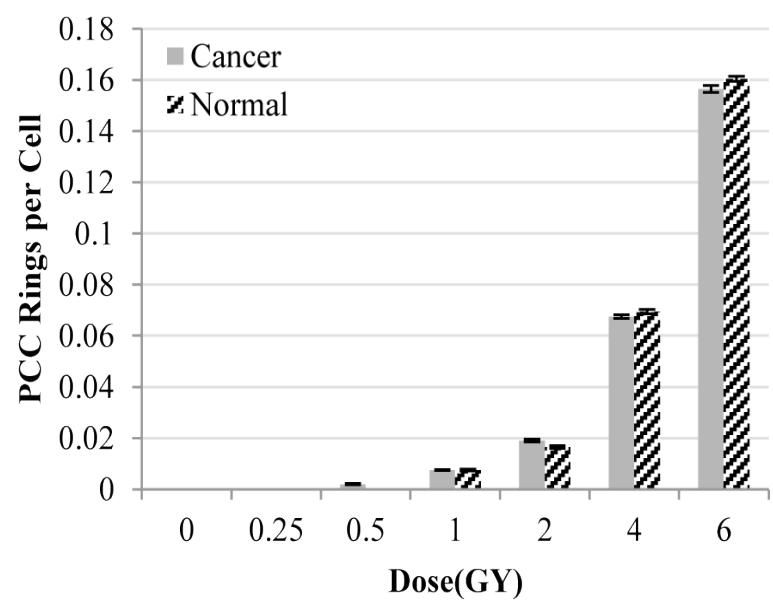

Figure 2: Comparison of the PCC rings yields between the healthy (Normal) individuals and prostate cancer patients at different radiation doses 
tients. Nowadays, physicians try to diagnose such cancers with screening tests and physical examinations as soon as possible. In this regard, cytogenetic tests are applied to find the ones who are predisposed to cancers. Thereafter, performing more specific and frequent tests on cases predisposed to cancer could be useful to increase the possibility of cancer diagnosis at early steps and stages.

Despite the high incidence and mortality of prostate cancer, cytogenetic tests have not been applied adequately to assess whether they can discriminate healthy individuals from predisposed ones or not. Some cytogenetic tests such as the MN assay are affected by interventional factors such as sex. But, in our study the sexuality had no effect on the results, as all the individuals were either healthy men or those having prostate cancer. The selection of individuals between ages of 50 to 70 also omitted the effect of age on the results [31,32].

In many studies, higher levels of radiosensitivity in cancerous patients comparing with normal individuals have been characterized by using cytogenetic tests. The majority of such tests have been done with the $\mathrm{MN}$ and dicentric assays wherein an ability to separate healthy individuals from cancerous patients has been observed in many experiments [15-18, 20, 21, 27]. Thus the MN assay was selected in this study. In addition, since the chemical PCC test has not yet been performed for comparing healthy and cancerous cases and no information about its efficiency in this regard has been reported, and specific effects of ionizing radiation on ring construction are reported [31], this test was selected and used simultaneously on our cases. Review of previous studies shows that the comparisons of healthy and cancerous cases from radiosensitivity point of view have been done just for one or two levels of radiation doses. Therefore, in our study 7 radiation doses were investigated to facilitate the comparison of dose-response curves in the two groups and also to determine the optimum dose in which the best discrimination between the groups can be demonstrated.

One of the most important studies done for comparing healthy individuals with prostate cancer patients from the raddiosensitivity point of view is that of Borgmann et al, [13]. They claimed that healthy and prostate cancer cases demonstrate no difference from radiosensitivity point of view based on the dicentric test and $\mathrm{G}_{0}$ phase, while they reported a significant difference based on $G_{2}$ phase. They came to this conclusion that the endpoints of the dicentric test might differ from MN assay considering other researchers showing differences between cancerous patients (other than prostate) and healthy individuals by using the $\mathrm{MN}$ test. Furthermore, they said that these endpoints might be different for various cancers. Our study was implemented to assess the radiosensitivity of healthy and prostate cancer cases by using the two cytogenetic tests including the $\mathrm{MN}$ assay and chemical PCC to characterize whether the amount of micronuclei or PCC rings after irradiation of the lymphocytes can help to separate the healthy individuals from cancerous patients. In other words, we tried to investigate whether the $\mathrm{MN}$ or PCC rings could be regarded as an indicator for the endpoints related to prostate cancer or not.

The analysis of the results revealed that the $\mathrm{MN}$ assay at doses from 0 to $4 \mathrm{~Gy}$ indicates significant differences between the yields of micronuclei $(\mathrm{MN} / \mathrm{BC})$ of the two groups at identical doses. However, at 6 Gy no such difference was detected. The most notable difference was observed at $1 \mathrm{~Gy}(\mathrm{P}=0.001)$. It is necessary to emphasize that Borgmann et al., performed their $\mathrm{G}_{0}$ experiment at only 2 dose levels of 0 and $6 \mathrm{~Gy}$. There was a significant difference between the MN yields at all of the radiation doses within each group in our study. If we were able to use FISH (Fluorescence In Situ Hybridization) technique for staining the MN slides, we could have scored the micronuclei with and without centromere from which scoring such micronuclei separately and their proportion might have helped to discriminate 
the healthy individuals and prostate cancer patients more accurately [33]. Regarding the NDI, this index is useful for cell cycle kinetic investigation and is an indicator for determining the defects that occur in cells after the mutagens like ionizing radiation. In this research, the NDI decreased significantly as the dose increased from 0.5 to 6 within healthy group and from 0.25 to 6 within cancerous group. The NDI in prostate cancer group was less than healthy ones at identical doses ranged from 0.5 to $6 \mathrm{~Gy}$, but only at 0.5 and $6 \mathrm{~Gy}$ their differences were significant. Whereas the NDI is utilized for investigating the development of cell cycle after mitosis induction, its difference between the two groups indicates more injuries in cancer cells due to irradiation [32-34].

Considering the chemical PCC test, there was no significant difference of the PCC rings yields (PCC rings/cell) between the healthy individuals and prostate cancer patients at identical radiation doses. However, there were significant differences among the PCC rings yields at different doses ranging from 0.5 to 6 Gy within each group. Theoretically, considering the result of applying calyculin A that condenses chromosomes at any phases of cell cycle and makes them recognizable, we expect to see more chromosome aberrations in the chemical PCC comparing with dicentric assay $[35,36]$. In case of viewing more chromosome aberrations, we expect the possibility of discrimination of healthy individual lymphocytes from cancerous patients to increase because of more susceptibility of cancerous patients to radiation. With reference to the ring construction mechanism in chromosomal injury, no ring will be expected to be seen at doses less than $1 \mathrm{~Gy}$. Detecting no difference between the PCC rings yields of the healthy and prostate cancer cases can confirm Borgmann et al., [13] consideration about endpoints. This means that the genomic problems of prostate cancer patients do not show themselves in the form of rings in the chemical PCC test, as they did not show themselves in dicentric test in Borgmann et al., [13] experiment. Instead of using giemsa, the PCC test could be done with the FISH method to stain the slides to provide the possibility of scoring dicentrics and other fragments [37-39]. In such a situation, scoring aberrations other than rings and their compositions may lead to find better criteria to discriminate healthy individuals from prostate cancer patients like MN method. Furthermore, as the PCC test can be applied at higher radiation doses, it can be suggested that this test is applied for the separation of healthy and cancerous cases at doses higher than $6 \mathrm{~Gy}$ [35-40]. It is also possible that impairing or destroying chromosome repair mechanisms of cells at higher radiation doses could lead to differentiate between healthy and cancerous individuals [41].

\section{Conclusion}

Our results indicated that, while the $\mathrm{MN}$ test can be considered as a reliable indicator of predisposition of prostate cancer, the chemical PCC test could not differentiate between healthy donors and prostate cancer patients at the dose range examined in this study. It is therefore recommended the using the chemical PCC test at higher dose levels is investigated to find out whether it has any advantage over the $\mathrm{MN}$ test as an indicator of predisposition of prostate cancer patients or not, examined in this study.

\section{Conflict of Interest}

None

\section{References}

1. Jackson SP. Sensing and repairing DNA doublestrand breaks. Carcinogenesis. 2002;23:687-96. doi: 10.1093/carcin/23.5.687. PubMed PMID: 12016139.

2. Matsuura S, Royba E, Akutsu SN, et al. Analysis of individual differences in radiosensitivity using genome editing. Ann ICRP. 2016;45:290-6. doi: 10.1177/0146645316633941. PubMed PMID: 27012844.

3. Baria K, Warren C, Roberts SA, West CM, Scott 
Lymphocyte Radiosensitivity of Prostate Cancer

D. Chromosomal radiosensitivity as a marker of predisposition to common cancers? Br J Cancer. 2001;84:892-6. doi: 10.1054/bjoc.2000.1701. PubMed PMID: 11286467. PubMed PMCID: 2363837.

4. Ward JF. The complexity of DNA damage: relevance to biological consequences. Int J Radiat Biol. 1994;66:427-32. doi: 10.1080/09553009414551401. PubMed PMID: 7983426.

5. Meschini R, Morucci E, Berni A, Lopez-Martinez W, Palitti $F$. Role of chromatin structure modulation by the histone deacetylase inhibitor trichostatin A on the radio-sensitivity of ataxia telangiectasia. Mutat Res. 2015;777:52-9. doi: 10.1016/j.mrfmmm.2015.04.009. PubMed PMID: 25942615.

6. B Baeyens A, Thierens H, Claes K, Poppe B, et al. Chromosomal radiosensitivity in breast cancer patients with a known or putative genetic predisposition. Br J Cancer. 2002;87:1379-85. doi: 10.1038/ sj.bjc.6600628. PubMed PMID: 12454765. PubMed PMCID: 2376291.

7. Bonassi S, Hagmar L, Stromberg U, et al. Chromosomal aberrations in lymphocytes predict human cancer independently of exposure to carcinogens. European Study Group on Cytogenetic Biomarkers and Health. Cancer Res. 2000;60:1619-25. PubMed PMID: 10749131.

8. Hagmar L, Brogger A, Hansteen IL, Heim S, et al. Cancer risk in humans predicted by increased levels of chromosomal aberrations in lymphocytes: Nordic study group on the health risk of chromosome damage. Cancer Res. 1994;54:2919-22. PubMed PMID: 8187078.

9. Bonassi S, Abbondandolo A, Camurri L, et al. Are chromosome aberrations in circulating lymphocytes predictive of future cancer onset in humans? Preliminary results of an Italian cohort study. Cancer Genet Cytogenet. 1995;79:133-5. doi: 10.1016/0165-4608(94)00131-T. PubMed PMID: 7889505.

10. Hagmar L, Bonassi S, Stromberg U, et al. Chromosomal aberrations in lymphocytes predict human cancer: a report from the European Study Group on Cytogenetic Biomarkers and Health (ESCH). Cancer Res. 1998;58:4117-21. PubMed PMID: 9751622.

11. Bonassi S, Norppa H, Ceppi M, et al. Chromosomal aberration frequency in lymphocytes predicts the risk of cancer: results from a pooled cohort study of 22358 subjects in 11 countries. Carcinogenesis. 2008;29:1178-83. doi: 10.1093/carcin/ bgn075. PubMed PMID: 18356148. PubMed PMCID: 2443275.

12. Scott $D$. Chromosomal radiosensitivity and low penetrance predisposition to cancer. Cytogenet Genome
Res. 2004;104:365-70. doi: 10.1159/000077517. PubMed PMID: 15162066.

13. Borgmann K, Raabe A, Reuther S, Szymczak S, et al. The potential role of G2- but not of G0-radiosensitivity for predisposition of prostate cancer. Radiother Oncol. 2010;96:19-24. doi: 10.1016/j. radonc.2010.04.018. PubMed PMID: 20452694.

14. Scott D, Spreadborough A, Levine E, Roberts SA. Genetic predisposition in breast cancer. Lancet. 1994;344:1444. doi: 10.1016/S01406736(94)90615-7. PubMed PMID: 7968110.

15. Slonina D, Gasinska A. Intrinsic radiosensitivity of healthy donors and cancer patients as determined by the lymphocyte micronucleus assay. Int J Radiat Biol. 1997;72:693-701. doi: 10.1080/095530097142852. PubMed PMID: 9416792.

16. Scott D, Barber JB, Levine EL, Burrill W, Roberts $S A$. Radiation-induced micronucleus induction in lymphocytes identifies a high frequency of radiosensitive cases among breast cancer patients: a test for predisposition? Br J Cancer. 1998;77:61420. doi: 10.1038/bjc.1998.98. PubMed PMID: 9484819. PubMed PMCID: 2149942.

17. Rothfuss A, Schutz $P$, Bochum S, Volm T, et al. Induced micronucleus frequencies in peripheral lymphocytes as a screening test for carriers of a BRCA1 mutation in breast cancer families. Cancer Res. 2000;60:390-4. PubMed PMID: 10667592.

18. Jagetia GC, Jayakrishnan A, Fernandes D, Vidyasagar MS. Evaluation of micronuclei frequency in the cultured peripheral blood lymphocytes of cancer patients before and after radiation treatment. Mutat Res. 2001;491:9-16. doi: 10.1016/S13835718(00)00132-7. PubMed PMID: 11287292.

19. Baria K, Warren C, Eden OB, et al. Chromosomal radiosensitivity in young cancer patients: possible evidence of genetic predisposition. Int J Radiat Biol. 2002;78:341-6. doi: 10.1080/09553000110117359. PubMed PMID: 12020425.

20. Mozdarani H, Mansouri Z, Haeri SA. Cytogenetic radiosensitivity of g0-lymphocytes of breast and esophageal cancer patients as determined by micronucleus assay. J Radiat Res. 2005;46:111-6. doi: 10.1269/jrr.46.111. PubMed PMID: 15802866.

21. Varga D, Hoegel J, Maier C, Jainta S, et al. On the difference of micronucleus frequencies in peripheral blood lymphocytes between breast cancer patients and controls. Mutagenesis. 2006;21:31320. doi: 10.1093/mutage/gel035. PubMed PMID: 16928695.

22. Lisowska $H$, Lankoff $A$, Wieczorek $A$, et al. Enhanced chromosomal radiosensitivity in peripheral blood lymphocytes of larynx cancer patients. Int J Radiat Oncol Biol Phys. 2006;66:1245-52. doi: 
10.1016/j.jjrobp.2006.07.1370. PubMed PMID: 17145539 .

23. Distel LV, Neubauer S, Keller U, et al. Individual differences in chromosomal aberrations after in vitro irradiation of cells from healthy individuals, cancer and cancer susceptibility syndrome patients. Radiother Oncol. 2006;81:257-63. doi: 10.1016/j.radonc.2006.10.012. PubMed PMID: 17113667.

24. Shahidi M, Mozdarani H, Bryant PE. Radiation sensitivity of leukocytes from healthy individuals and breast cancer patients as measured by the alkaline and neutral comet assay. Cancer Lett. 2007;257:26373. doi: 10.1016/j.canlet.2007.08.002. PubMed PMID: 17881118.

25. Pantelias GE, Terzoudi GI. A standardized G2-assay for the prediction of individual radiosensitivity. Radiother Oncol. 2011;101:28-34. doi: 10.1016/j.radonc.2011.09.021. PubMed PMID: 22014898.

26. Ryabchenko NM, Glavin OA, Shtefura VV, Anikushko MF. Chromosomal radiosensitivity in Ukrainian breast cancer patients and healthy individuals. Exp Oncol. 2012;34:121-4. PubMed PMID: 23013765.

27. Encheva E, Deleva S, Hristova R, Hadjidekova V, Hadjieva T. Investigating micronucleus assay applicability for prediction of normal tissue intrinsic radiosensitivity in gynecological cancer patients. Rep Pract Oncol Radiother. 2011;17:24-31. doi: 10.1016/j.rpor.2011.10.002. PubMed PMID: 24376993. PubMed PMCID: 3863151.

28. Farhan F, Azimi C, Mahmoodi M, Mohagheghi M-A, Farzanfar F, Noor-Mohammadi A, et al. Chromosomal radiosensitivity in lymphocytes of head and neck cancer patients as determind by mironucleus and G2 assays. Tehran University Medical Journal TUMS Publications. 2016;74:36-41.

29. Scott D, Barber JB, Spreadborough AR, Burrill W, Roberts SA. Increased chromosomal radiosensitivity in breast cancer patients: a comparison of two assays. Int $J$ Radiat Biol. 1999;75:1-10. doi: 10.1080/095530099140744. PubMed PMID: 9972785.

30. Fenech M. Cytokinesis-block micronucleus cytome assay. Nat Protoc. 2007;2:1084-104. doi: 10.1038/ nprot.2007.77. PubMed PMID: 17546000.

31. Pajic J, Rakic B, Jovicic D, Milovanovic A. Construction of dose response calibration curves for dicentrics and micronuclei for $\mathrm{X}$ radiation in a Serbian population. Mutat Res Genet Toxicol Environ Mutagen. 2014;773:23-8. doi: 10.1016/j.mrgentox.2014.07.009. PubMed PMID: 25308702.

32. WHO. Cytogenetic dosimetry: applications in preparedness for and response to radiation emergencies. Vienna: International Atomic Energy Agency; 2011.
33. Pejchal J, Vasilieva V, Hristozova M, Vilasová Z, Vávrová J, Alyakov M, et al. Cytokinesis-block micronucleus (CBMN) assay/CBMN cytome assay in human lymphocytes after in vitro irradiation and its use in biodosimetry. Mil Med Sci Lett. 2011;80:2837. doi: $10.31482 / \mathrm{mmsl} .2011 .004$.

34. Rastkhah E, Zakeri F, Ghoranneviss M, et al. The cytokinesis-blocked micronucleus assay: dose-response calibration curve, background frequency in the population and dose estimation. Radiat Environ Biophys. 2016;55:41-51. doi: 10.1007/s00411015-0624-3. PubMed PMID: 26507139.

35. Sommer S, Buraczewska I, Sikorska K, et al. The rapid interphase chromosome assay (RICA) implementation: comparison with other PCC methods. Nukleonika. 2015;60:933-41. doi: 10.1515/nuka2015-0147.

36. Durante Y, Furusawa E, Gotoh M. Technical Report A simple method for simultaneous interphasemetaphase chromosome analysis in biodosimetry. International journal of radiation biology. 1998;74:457-62. doi: 10.1080/095530098141320.

37. Karachristou I, Karakosta M, Pantelias A, et al. Triage biodosimetry using centromeric/telomeric PNA probes and Giemsa staining to score dicentrics or excess fragments in non-stimulated lymphocyte prematurely condensed chromosomes. Mutat Res Genet Toxicol Environ Mutagen. 2015;793:107-14. doi: 10.1016/j.mrgentox.2015.06.013. PubMed PMID: 26520380.

38. Suto $\mathrm{Y}$, Gotoh $T$, Noda T, Akiyama M, Owaki $M$, Darroudi $F$, et al. Assessing the applicability of FISH-based prematurely condensed dicentric chromosome assay in triage biodosimetry. Health Phys. 2015;108:371-6. doi: 10.1097/ HP. 0000000000000182 . PubMed PMID: 25627950.

39. M'Kacher R, El Maalouf E, Terzoudi G, et al. Detection and automated scoring of dicentric chromosomes in nonstimulated lymphocyte prematurely condensed chromosomes after telomere and centromere staining. Int J Radiat Oncol Biol Phys. 2015;91:640-9. doi: 10.1016/j.ijrobp.2014.10.048. PubMed PMID: 25596111.

40. Hatzi VI, Terzoudi GI, Paraskevopoulou C, et al. The use of premature chromosome condensation to study in interphase cells the influence of environmental factors on human genetic material. Scientific World Journal. 2006;6:1174-90. doi: 10.1100/ tsw.2006.210. PubMed PMID: 17013523.

41. Lindholm C, Stricklin D, Jaworska A, et al. Premature chromosome condensation (PCC) assay for dose assessment in mass casualty accidents. Radiat Res. 2010;173:71-8. doi: 10.1667/RR1843.1. PubMed PMID: 20041761. 